\title{
Role of topical heparin in the management of burns: experience in a district government hospital of Karnataka in South India
}

\author{
Ashish Gupta1, Thangam J. Verghese ${ }^{2}$, Priyanka Gupta ${ }^{3}$, Ashok K. Gupta ${ }^{4}$ \\ ${ }^{1}$ Department of Plastic and Microvascular Surgery, SPS Apollo Hospitals, Ludhiana 141003, Punjab, India. \\ ${ }^{2}$ Department of Surgery, Kasturba Medical College, Mangalore 575001, Karnataka, India. \\ ${ }^{3}$ Department of Pediatric Hematology and Oncology, SPS Apollo Hospitals, Ludhiana 141003, Punjab, India. \\ ${ }^{4}$ Department of Plastic Surgery and Burns, DMCH, Ludhiana 141001, Punjab, India.
}

Address for correspondence: Dr. Ashish Gupta, Department of Plastic and Microvascular Surgery, SPS Apollo Hospitals, Sherpur Chowk, GT Road, Ludhiana 141003, Punjab, India. E-mail: docashish2001@gmail.com

\begin{abstract}
Aim: Heparin is a multifaceted compound with uses not only as an anticoagulant, but also as an anti-inflammatory, anti-allergenic, anti-histaminic, anti-serotonin, anti-proteolytic and neoangiogenic agent. The aim of the study was to study the effect of topical heparin in the management of second-degree burns. Methods: Between December 2005 and January 2007, 60 consecutive patients, aged 10-60 years, with first-and second-degree thermal injuries ranging from $10 \%$ to $60 \%$, were randomly enrolled in the study divided into a control group $(\mathrm{C})$ and a heparin group $(\mathrm{H})$ of 30 patients each. Results: Patients treated with topical heparin experienced statistically significant improved pain relief, faster healing, fewer complications and shorter hospital stays. The majority of the patients admitted were in an economically productive age group and were predominantly female. The distribution between the two groups according to age, type of burns and extent of burns was not statistically different. Conclusion: The current study demonstrates the efficacy of topical heparin in the treatment of first- and second-degree burns.
\end{abstract}

Key words:

Benefits, burns, cost, epidemiology, heparin

\section{INTRODUCTION}

The earliest account of the treatment of burns dates back to the Egyptian period and the Ebers Papyrus. Rhazes (850-923 AD) prescribed rosewater cooled by snow for burn wounds, and Avicenna (980-1037 AD) described the importance of using cold water in the management of burn injuries. ${ }^{[1]}$

Surgeons have advanced considerably from the use of oil-soaked cloth applications to the use of primary

\begin{tabular}{|l|l|}
\multicolumn{2}{|c|}{ Access this article online } \\
\hline Quick Response Code: & Website: \\
\hline & www.parjournal.net \\
\cline { 2 - 3 } & \\
\hline
\end{tabular}

tangential excisions and skin grafts with recombinant skin. With the advent of dedicated burn critical care units, there has been a concomitant improvement in the survival rates of critically injured burns patients and their return to society as economically productive members.

Heparin is a multifaceted compound with anti-inflammatory, anti-allergenic, anti-histaminic, anti-serotonin and antiproteolytic enzyme properties. It has been used in both parenteral and topical forms in the management of thermal injuries to prevent burn extension, limit cutaneous tissue loss, promote faster healing with fewer contractures, relieve of pain, reduce tissue edema and weeping, prevent infection, and to promote revascularization, granulation and reepithelialization of deeply burned tissue. This study was conducted to study the role of topical heparin in the management of thermal burns and to validate its efficacy and safety in a District Government Hospital in South India. 


\section{METHODS}

A total of 326 patients with burns injuries were admitted to Government Wenlock Hospital, Mangalore, between December 2005 and January 2007. The first consecutive 60 patients with $10-60 \%$ second degree burns between the ages of 10 and 60 were enrolled in the study. Patients with liver disease, renal disorders, a blood-coagulating diathesis, an allergy to heparin, an active peptic ulcer, thrombocytopenia, active bleeding or potential bleeding from trauma were excluded. Patients who met the inclusion criteria were randomly assigned a control group (Group C) or heparin group (Group H). Thirty patients were started on topical heparin (Group $\mathrm{H}$ ), while the other 30 patients in the control group (Group C) were treated with conventional dressings with silver sulfadiazine, intravenous antibiotics, analgesics and intravenous fluids.

The dose of heparin required for topical application was calculated to be $100,000 \mathrm{IU} / 15 \%$ burn surface area (BSA) per day in 3-4 divided doses. The medication was applied to the burnt surface drop by drop with a $50 \mathrm{~mL}$ syringe, until the pain was relieved, repeated for 2-4 times until blanching occurred. Beginning on the 2nd day, heparin was applied twice a day, using a diminishing quantity for 1 week.

Blisters were rinsed with heparin solution via hypodermic syringe and were not de-roofed. Blood was drawn to test for bleeding time, clotting time, and activated partial thromboplastin time, in addition to routine blood investigations.

Relief of pain as recorded by a visual analog scale, healing of wounds, dose of heparin, complications, mortality and duration of hospital stay were reported and analyzed. This was a single-blinded study that was approved by the Ethics Committee of the Institute. Written informed consent was obtained from the patients or guardians.

\section{RESULTS}

Among the 60 patients enrolled in the study, the age distribution between the two groups was not significantly different [Table 1]. The majority of the patients admitted were in the economically productive age group of 31-40 years old (19 patients, 31\%).

There were equal numbers of male and female patients in Group H. The gender distribution among the two groups was not statistically significant [Table 2].

The study showed a statistically significant $(P=0.017)$ difference in the cause of burns between males and females. Accidental burns were seen in 33 patients as compared to 21 patients with homicidal intent, and 6 patients with suicidal aim. Males (18 patients) figured predominantly in the accidental group, whereas females were significantly more represented in the homicidal (17 patients) and suicidal (5 patients) subgroups [Table 3].
The distribution of the patients in the Group $\mathrm{H}$ and Group $C$ cohorts as per the cause of burns was statistically not significant $(P=0.176)$ and is depicted in Figure 1 .

The stratification of patients according to the extent of the thermal injury has been depicted in Table 4.

The division of burn patients in Groups $\mathrm{H}$ and $\mathrm{C}$ with respect to their duration of stay in the hospital revealed an earlier discharge from the hospital in Group $\mathrm{H}$, except in cases of extensive burns of more than $50 \%$ BSA [Table 5]. The mean duration of hospital stay was significantly less in the Group $\mathrm{H}$ compared the Group C, in $10-20 \%$ burns (13 vs. 26 days), 20-30\% burns (23 vs. 41 days), and 30-40\% burns (26 vs. 67 days). A shorter hospital stay has many positive ramifications in an Indian family, in addition to the reduced economic burden of treatment.

Patients in Group $\mathrm{C}$ were prone to numerous complications as compared to Group $\mathrm{H}$. The occurrence of these complications as depicted in Table 6 was highly statistically

Table 1: Age distribution of the patients under evaluation

\begin{tabular}{lcc}
\hline Age group (years) & \multicolumn{2}{c}{ Number of patients } \\
\cline { 2 - 3 } & Group H & Group C \\
\hline $10-20$ & 6 & 6 \\
$21-30$ & 6 & 8 \\
$31-40$ & 11 & 8 \\
$41-50$ & 4 & 3 \\
$51-60$ & 3 & 5 \\
Total & 30 & 30 \\
\hline
\end{tabular}

Table 2: Distribution of patients according to gender

\begin{tabular}{lcc}
\hline Gender & \multicolumn{2}{c}{ Number of patients } \\
\cline { 2 - 3 } & Group H & Group C \\
\hline Male & 15 & 8 \\
Female & 15 & 22 \\
\hline
\end{tabular}

Table 3: Cause of burns

\begin{tabular}{lcc}
\hline \multirow{2}{*}{ Cause of burns } & \multicolumn{2}{c}{ Number of patients } \\
\cline { 2 - 3 } & Male & Female \\
\hline Accidental & 18 & 15 \\
Homicidal & 4 & 17 \\
Suicidal & 1 & 5 \\
Total & 23 & 37 \\
\hline
\end{tabular}

Table 4: Number of patients according to extent of thermal injury

\begin{tabular}{lcc}
\hline $\begin{array}{l}\text { Percentage of burns } \\
(\%)\end{array}$ & \multicolumn{2}{c}{ Number of patients } \\
\cline { 2 - 3 } & Group H & Group C \\
\hline $10-20$ & 8 & 10 \\
$21-30$ & 10 & 5 \\
$31-40$ & 9 & 7 \\
$41-50$ & 0 & 4 \\
$51-60$ & 3 & 4
\end{tabular}


significant $(P=0.008)$. The majority of Group $C$ patients (24 patients) had wound contamination by the 5 th postburn day, whereas in Group $\mathrm{H}$ only 4 patients developed wound infection, a highly statistically significant difference $(P<0.001)$ [Figure 2]. None of the patients in Group $\mathrm{H}$ had weeping wounds, as compared to Group $\mathrm{C}$ in which $76.7 \%$ of the patients developed weeping wounds $(P<0.001)$.

A reduction in infections was observed in nonweeping wounds in Group $\mathrm{H}$ as compared to Group C.

Fisher's exact test was used to calculate the significance of the lower analgesic requirement in Group $\mathrm{H}$ as compared to Group C [Table 7]. The lower requirement for opioids

Table 5: Duration of hospitalization was significantly less than patients on conventional therapy

\begin{tabular}{lccc}
\hline $\begin{array}{l}\text { Percentage of burns } \\
(\%)\end{array}$ & \multicolumn{2}{c}{$\begin{array}{c}\text { Mean duration of } \\
\text { hospitalization }\end{array}$} & $P$ \\
\cline { 2 - 3 } & Group H & Group C & \\
\hline $10-20$ & 13.6 & 26.2 & 0.018 \\
$21-30$ & 23.2 & 41 & 0.003 \\
$31-40$ & 26.4 & 67.9 & 0.001 \\
$41-50$ & 0 & 45 & \\
$51-60$ & 47.7 & 38 & 0.289 \\
\hline
\end{tabular}

Table 6: Complications

\begin{tabular}{lcc}
\hline Complications & \multicolumn{2}{c}{ Number of patients } \\
\cline { 2 - 3 } & Group H & Group C \\
\hline Aspiration pneumonia & 0 & 3 \\
Atelectasis & 0 & 1 \\
Deep venous thrombosis & 0 & 5 \\
Pulmonary embolism & 0 & 1 \\
Septicemia & 1 & 3 \\
Urinary tract infection & 3 & 6 \\
No complications & 26 & 11 \\
\hline
\end{tabular}

Table 7: Use of opioid analgesic

\begin{tabular}{lcc}
\hline Number of doses per day & \multicolumn{2}{c}{ Number of patients } \\
\cline { 2 - 3 } & Group H & Group C \\
\hline $1-2$ & 6 & 2 \\
$3-4$ & 0 & 28 \\
\hline
\end{tabular}

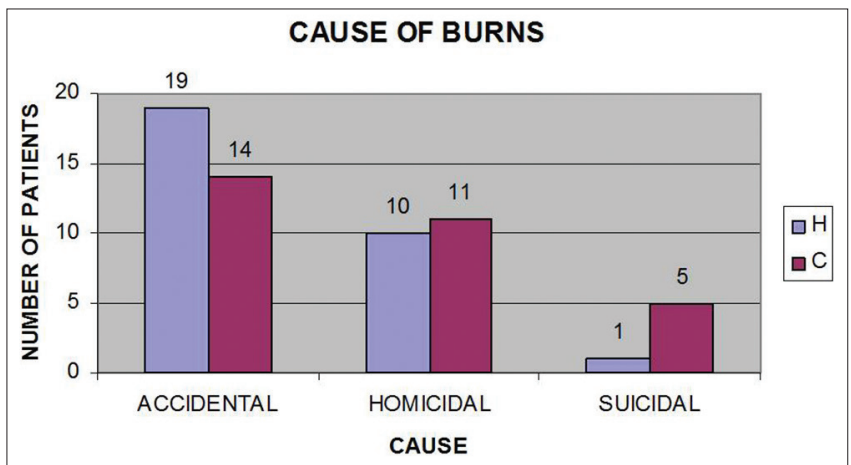

Figure 1: Distribution of patients according etiology among heparin and control groups in Group $\mathrm{H}$ had a positive effect on care, as patients were significantly more alert $(P<0.001)$.

There were fewer mortalities in Group $\mathrm{H}$ (1 patient) as compared to Group C (5 patients), but this difference was not statistically significant $(P=0.197)$. The decreased mortality rate could not statistically be attributed to the effect of heparin alone.

\section{DISCUSSION}

Sushruta, considered to be the father of Indian surgery, described the clinical symptoms of burnt patients in 800 BC. In 1607, Fabricus Hildnus ${ }^{[1]}$ of Switzerland provided the first printed extensive description of burns, their classification and treatment in his book "De Combustionibus."

Heparin has been shown to be very effective in the treatment of burns ${ }^{[2]}$ in a number of studies conducted in different centers across the globe. ${ }^{[3]}$ The use of heparin in burns has been shown to maintain blood circulation, inhibit blood clotting and infarctions, relieve pain, limit inflammation, revascularize ischemic tissue, enhance granulation, regulate collagen, and reduce scarring and contractures. ${ }^{[4]}$

The addition of heparin affordably improved burn care in the current study. A majority of the burns were accidental (46.7\% of Group C and $63.3 \%$ of Group H), while an appreciable number were homicidal in intent (36.7\% of Group C and 33.3\% of Group H).

The pain, erythema, and edema were reduced in patients who received treatment with heparin. The relief of pain with the use of heparin was remarkable as assessed on the visual analog scale as compared to the level of pain experienced in Group C. There was a direct relationship between the size of burns and the amount of heparin required to produce healing. The reduced use of pain medication and associated reduced side effects permitted Group $\mathrm{H}$ patients, who were more alert and cheerful, to ambulate sooner and participate in their burn treatment. ${ }^{[2]}$

Irrigation of blisters in Group $\mathrm{H}$ removed the inflammatory exudates, and the skin functioned as an autologous biological dressing. Smooth new skin was evident beneath the dried thin blister when it usually flaked off in 10-14 days.

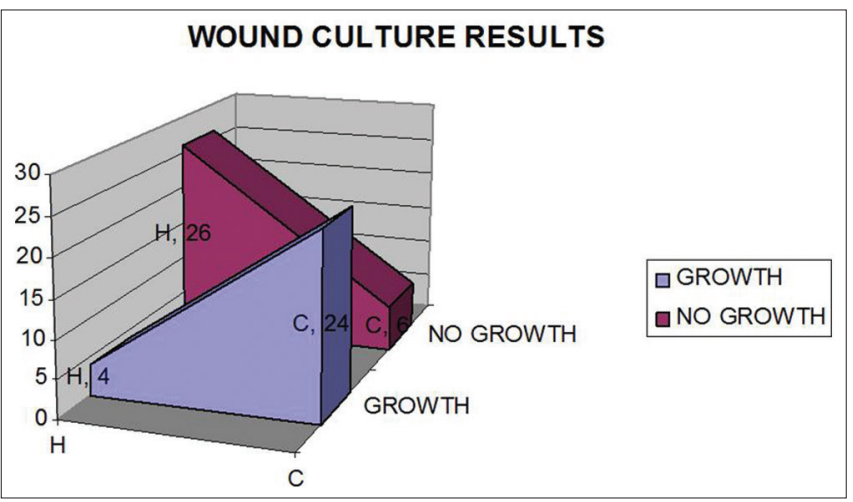

Figure 2: Wound culture and growths 
The revascularization of ischemic tissue was the key feature preventing extension of burns and hence a better outcome in patients treated with heparin. These improvements were presumed to be a function of heparin's neoangiogenic effects. ${ }^{[5-7]}$

Prior studies have suggested that orally administered antibiotics can reach burns secondary to an increase in blood flow mediated by the enhanced neoangiogenic-revascularization of the ischemic tissue. ${ }^{[8-10]}$ A reduction in intestinal bacterial translocation and sepsis found in another study may be another partial explanation for the reduction of infection seen in the current study. ${ }^{[1]}$

The safety of large doses of topical heparin was demonstrated by laboratory determinations of blood clotting times, which were not altered. No bleeding problems or other serious complications occurred. ${ }^{[12]}$

There were fewer skin grafting procedures required in Group $\mathrm{H}$ as compared to Group $\mathrm{C}$, but this finding was not statistically significant. Mortality rates in Group $\mathrm{H}$ were lower than in Group C, with all of the deaths in the latter group occurring in 45-60\% BSA injuries. Notably, there were more suicide patients in Group C (16.7\%) as compared to Group $\mathrm{H}(3.3 \%)$, and suicide burns tend to be more severe. Early tangential excision and skin grafting are not practiced at our institute due to issues of nonavailability of blood products and lack of consent for surgery. Additional variables contributing to a prolonged hospital stay include the availability of free treatment in a government-aided hospital in conjunction with poor familial support.

In 1967, Dr. Saliba MJ Jr, originally published a report of the beneficial effects of intravenous heparin in large doses as a topical spray used to treat extensive burns

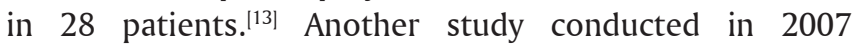
showed the utility of the use of topical heparin in treating 100 patients with thermal injuries. ${ }^{[14]}$ Since that time, numerous studies have confirmed these results. ${ }^{[15]}$

In conclusion, even as research for newer modalities in burn wound management continues, the authors find that some traditional modalities still have clinical relevance. Although there are numerous studies supporting the use of heparin in the treatment of burn wound management, many of these are uncontrolled and inadequately define the appropriate treatment and outcomes. Further research is needed to assess the clinical utility of using heparin in the treatment of burn injuries. ${ }^{[15]}$

\section{REFERRENCES}

I. Teot L, Otman S, Brancati A, Mittermayr R. Burn scar treatment. In: Kamolz LP, Jescheke MG, Horch RE, Küntscher M, Brychta P, editors. Handbook of Burns. Vienna: Springer; 2012. p. 55-67.

2. Masoud M, Wani AH, Darzi MA. Topical heparin versus conventional treatment in acute burns: a comparative study. Indian J Burns 20।4;22:43-50.

3. Alrich EM. The effect of heparin on the circulating blood plasma and proteins in experimental burns. Surgery 1949;25:676-80.

4. Lu J, Xu T, Yang M, Xu XW, Wu B. Heparin for the treatment of burns (Protocol). Cochrane Database Syst Rev 201 I; I2:CD009483.

5. Reyes A, Astiazaran JA, Chavez CC, Jaramillo F, Saliba MJ. Burns treated with and without heparin: controlled use in a thermal disaster. Ann Burns Fire Disasters 200I;|14:183-91.

6. Saliba MJ Jr, editor. The Effects of Heparian in the Treatment of Burns. Proceedings of International Meeting; 1994 Feb 24-27; San Diego, CA, USA.

7. Saliba MJ Jr. Heparin in the treatment of burns. JAMA 1967;200:650.

8. Church D, Elsayed S, Reid O, Winston B, Lindsay R. Burn wound infections. Clin Microbiol Rev 2006; 19:403-34.

9. Saliba MJ Jr. Heparin efficacy in burns. II. Human thermal burn treatment with large doses of topical and parenteral heparin. Aerosp Med 1970;41:I302-6.

10. Saliba MJ Jr, Dempsey WC, Kruggel JL. Large burns in humans. Treatment with heparin. JAMA 1973;225:26I-9.

II. Ferreira Chacon JM, Mello de Andrea ML, Blanes L, Ferreira LM. Effects of topical application of $10,000 \mathrm{IU}$ heparin on patients with perineal dermatitis and second-degree burns treated in a public pediatric hospital. J Tissue Viability 2010;19:150-8.

12. Elsayed E, Becker RC. The impact of heparin compounds on cellular inflammatory responses: a construct for future investigation and pharmaceutical development. J Thromb Thrombolysis 2003; 15: I I-8.

13. Saliba MJ Jr. The effects and uses of heparin in the care of burns that improves treatment and enhances the quality of life. Acta Chir Plast 1997;39:13-6.

14. Venakatachalapathy TS, Mohan Kumar S, Saliba MJ. A comparative study of burns treated with topical heparin and without heparin. Ann Burns Fire Disasters 2007;20:189-98.

15. Agbenorku P, Fugar S, Akpaloo J, Hoyte-Williams PE, Alhassan Z, Agyei F. Management of severe burn injuries with topical heparin: the first evidence-based study in Ghana. Int J Burns Trauma 2013;3:30-6.

How to cite this article: Gupta A, Verghese TJ, Gupta P, Gupta AK. Role of topical heparin in the management of burns: experience in a district government hospital of Karnataka in South India. Plast Aesthet Res 2015;2:111-4.

Source of Support: Nil, Conflict of Interest: None declared.

Received: 13-07-2014; Accepted: 29-03-2015 